\title{
Some Features of DC Concentration Distribution in Blood Serum and Tissues of Rats
}

\author{
Pavlova O.N. ${ }^{1, *}$ Gulenko O.N. ${ }^{2}$ Boriskin P.V. ${ }^{3}$ Grigoryeva Yu.V. ${ }^{4}$ Devyatkin A.A. ${ }^{5}$ \\ Milyutina D.I. ${ }^{5}$ Sultanov F.P. ${ }^{5}$ Tulaeva O.N. ${ }^{4}$
}

\author{
${ }^{1}$ LLC "TestGen", Ulyanovsk, Russia \\ ${ }^{2}$ Samara State University of Railway Engineering, Samara, Russia \\ ${ }^{3}$ Kazan State Academy of Veterinary Medicine named after N.E. Bauman, Kazan, Republic of Tatarstan, Russia \\ ${ }^{4}$ Samara State Medicine University, Samara, Russia \\ ${ }^{5}$ Mari State University, Yoshkar-Ola, the Republic of Mari El, Russia \\ *Corresponding author. Email: casiopeya13@mail.ru
}

\begin{abstract}
One of the mechanisms for maintaining homeostasis is lipid peroxidation (LPO). The influence of external and internal factors affecting the body can change the dynamics of LPO processes, causing numerous disturbances in the systems. The dynamics of LPO processes can be estimated by changing concentrations of intermediate oxidation products - diene conjugates (DC). The aim of the article is to identify features of the distribution of DC concentrations in blood serum and tissues of white rats. New results of a nonparametric correlation analysis are presented to assess the relationship between the distribution of DC concentrations in blood serum and tissues of rats.
\end{abstract}

Keywords: oxidative stress, diene conjugates, lipid peroxidation, blood serum, liver, brain, heart, skeletal muscle

\section{INTRODUCTION}

The optimal combination of free radical oxidation and peroxidation of biosubstrates contributes to the homeostasis and normal functioning of the antioxidant system which is the combination of all protective mechanisms at the cellular, tissue and organ levels.

The combined action of adverse external and internal factors leads to increased formation of active oxygen forms (AOF), such as superoxide anion, hydrogen peroxide, hydroxyl. Free radicals are highly reagent, interacting with proteins and lipids, change the dynamics of the physiological processes of the body, and intensify aging. At the same time, an indicator of the adaptive potential of the body is the level of control of intensity of lipid peroxidation.

Any pathological processes dramatically intensify free radical oxidation (SRO), stimulating an increase in the level of prooxidants, which enhance SRO. Therefore, SRO becomes a non-specific pathogenetic link, triggering a functional imbalance in the non-enzymatic and enzymatic links of the antioxidant defense system.

Elements of the antioxidant defense cannot cope with their expression, membrane destruction is provoked and, as a result, oxidative stress is produced. Oxidative stress is the process of a cell damage as a result of the action of free radicals. Moreover, this process is not negative. It can be a protective mechanism fighting against antigens. Reactive forms of oxygen can act as mediators in the transmission of nerve impulses.

Tissues and organ systems have a different degree of sensitivity to exposure (ROS). This is probably due to the dynamic perception of antioxidant enzymes and the specific metabolism of various tissues provided by the intracellular redox potential (redox potential), which is a derivative of all biochemical reactions of the cell.

The physiological state can be assessed by analyzing the imbalance between lipid peroxidation and the antioxidant system $[2,4,7,10]$.

The state of lipid peroxidation is estimated by the content of lipid peroxidation intermediate products, which include: lipid hydroperoxides, aldehydes, ketones, a number of low molecular weight acids (formic, acetic, butyric). These products are toxic agents that violate the functionality of the membranes and full metabolism. In this case, diene conjugates, peroxide radicals, malondialdehyde, Schiff bases are synthesized.

The synthesis of diene conjugates (DC) reflects the early stages of oxidation.

During free radical oxidation of arachidonic acid, hydrogen is detached in the $\alpha$-position with respect to the double bond, which leads to the displacement of this double bond with the DC formation [9]. The diene conjugates which are primary products of lipid peroxidation are toxic metabolites that have a damaging effect on lipoproteins, proteins, enzymes, and nucleic acids [5, 8]. 
Thus, the aim of the article is to study the relationship between the distribution of DC concentrations in the blood serum and tissues of rats.

To achieve this goal, the following tasks have to be solved: to determine the concentration of diene conjugates in the blood serum and tissues of liver, brain, heart, and skeletal muscle of rats; to reveal the relationship between the distribution of DC concentration in blood serum and tissues.

\section{METHODS AND MATERIALS}

The study was carried out on 150 white adult healthy male rats weighing 190-210 g. They were kept in a vivarium under standard conditions.

The concentration of diene conjugates was determined by the spectrometric method [1].

The method is based on the determination of the content of primary lipid peroxidation products in the blood by absorbing the monochromatic light flux by the lipid extract in the ultraviolet region of the spectrum, since molecules with two conjugated bonds (diene conjugates) have a maximum adsorption at $233 \mathrm{~nm}$.

A mixture of heptane: isopropanol (1: 1) was added to $0.2 \mathrm{ml}$ of plasma (tissue homogenate) and shaken for $10-15$ minutes with a laboratory shaker. $1 \mathrm{ml}$ of $\mathrm{HCl}$ solution $(\mathrm{pH}=2)$ and $2 \mathrm{ml}$ of heptane were added to the tube, and vigorously shaken. After settling and stratification of the mixture into phases (after 20-25 min), the upper heptane layer was used to determine acyl hydroperoxides according to the degree of light absorption at a wavelength of $\lambda-233 \mathrm{~nm}$ (A233).

A sample containing $0.2 \mathrm{ml}$ of water was used as a control sample.

The calculation of the content of primary lipid peroxidation products was carried out in relative units by formula:

Table 1 Distribution of DC concentration values in blood serum and tissues of white rats

\begin{tabular}{|l|c|c|c|c|c|c|c|c|c|}
\hline $\begin{array}{l}\text { Descriptive Statistics of } \\
\text { Associated Groups }\end{array}$ & N & M & Me & Min & Max & 25 Perc & $\mathbf{7 5}$ Perc & 10 Perc & 90 Perc \\
\hline blood serum & 150 & 34.31 & 34.30 & 32.90 & 35.60 & 33.90 & 34.70 & 33.50 & 35.10 \\
\hline liver & 150 & 26.56 & 26.50 & 25.10 & 27.90 & 26.10 & 26.90 & 25.65 & 27.55 \\
\hline brain & 150 & 16.36 & 16.40 & 15.10 & 17.90 & 15.80 & 16.80 & 15.40 & 17.40 \\
\hline heart & 150 & 58.24 & 58.30 & 57.10 & 59.80 & 57.60 & 58.70 & 57.30 & 59.20 \\
\hline skeletal muscle & 150 & 30.24 & 30.20 & 28.50 & 31.90 & 29.50 & 30.80 & 29.10 & 31.50 \\
\hline
\end{tabular}

To assess the relationship between the distribution of DC concentrations in blood serum and tissues, correlations were studied using the Spearman's nonparametric correlation coefficient (Table 2), and the gamma correlation and Kendell Tau coefficients (Table 3).
$\mathrm{A} 233$ per $1 \mathrm{ml}$ of plasma $=\mathrm{A} 233 \cdot \mathrm{VE}: \mathrm{Vpl}=$ $=(\mathrm{A} 233 \cdot 4): 0.2=\mathrm{A} 233 \cdot 206$

where A233 is optical density of the experimental sample at $\lambda-233 \mathrm{~nm} ; \mathrm{VE}=4 \mathrm{ml}$ - final volume of the heptane extract (in $\mathrm{ml}$ ); $\mathrm{Upl}=0.2 \mathrm{ml}$ - the volume of blood plasma (tissue homogenate).

The calculation was made on: $1 \mathrm{mg}$ of lipids, for which the total lipid content was determined by the sulfophosphovaniline method.

The concentration of diene conjugates was studied in the tissues of liver, heart, brain and skeletal muscle as well as in blood serum. To do this, rats were killed in accordance with ethical standards under ether anesthesia by decapitation, then the tissues were extracted, washed with physiological saline and immediately frozen.

Homogenates were prepared by mechanical grinding of tissues weighing $1 \mathrm{~g}$ with $9 \mathrm{ml}$ of Tris buffer ( $\mathrm{pH} 7.4$ ), at a speed of $5000 \mathrm{rpm}$ in a double-walled vessel, constantly cooled with running water [6].

The digital material was statistically processed using a Spearman nonparametric correlation analysis, as well as gamma correlation and Kendell Tau coefficients.

\section{RESULTS}

An array of numerical data on the DC concentration in blood serum and tissues was obtained. The results were processed (Table 1). At the first stage, a check for compliance with the normal distribution of DC concentration in blood serum and tissues was carried out. The one-sample Kolmogorov-Smirnov criterion was used. It was found that the DC concentration distribution in blood serum and tissues was not normal. During further statistical processing, nonparametric analysis methods were used. 
Table 2 Spearman's correlation coefficient for distribution of DC concentration in blood serum and tissues and $\mathrm{p}$ value

\begin{tabular}{|l|l|l|l|}
\hline Spearman correlation & Valid N & Spearman R & p-level \\
\hline blood serum \& liver & 150 & -0.159332 & 0.051469 \\
\hline blood serum \& brain & $\mathbf{1 5 0}$ & $\mathbf{0 . 2 0 7 9 7 6}$ & $\mathbf{0 . 0 1 0 6 5 4}$ \\
\hline blood serum \& heart & 150 & 0.119623 & 0.144822 \\
\hline blood serum \& muscle & 150 & 0.022562 & 0.784048 \\
\hline
\end{tabular}

Table 3 Gamma correlation and Kendell Tau correlation coefficients for the distribution of DC concentration in blood serum and tissues

MD pairwise deleted Marked correlations are significant at $\mathrm{p}<.05000$

\begin{tabular}{|l|l|l|l|l|}
\hline & Valid N & Gamma & Z & p-level \\
\hline blood serum \& liver & 150 & -0.118381 & -2.02668 & 0.042695 \\
\hline blood serum \& brain & 150 & 0.156569 & 2.68899 & 0.007167 \\
\hline blood serum \& heart & 150 & 0.086370 & 1.48474 & 0.137613 \\
\hline blood serum \& muscle & 150 & 0.015628 & 0.26986 & 0.787270 \\
\hline
\end{tabular}

MD pairwise deleted Marked correlations are significant at $\mathrm{p}<.05000$

\begin{tabular}{|l|l|l|l|l|}
\hline & Valid N & Kendall Tau & Z & p-level \\
\hline blood serum \& liver & 150 & -0.111607 & -2.02668 & 0.042695 \\
\hline blood serum \& brain Г & 150 & 0.148079 & 2.68899 & 0.007167 \\
\hline blood serum \& heart & 150 & 0.081763 & 1.48474 & 0.137613 \\
\hline blood serum \& muscle & 150 & 0.014861 & 0.26986 & 0.787270 \\
\hline
\end{tabular}

Table 3 shows that when studying the distribution of DC concentrations in blood serum and tissues, a direct reliable weak correlation was found between the DC concentrations in blood serum and brain tissues (Gamma 0.16 at $\mathrm{p} \leq 0,007167$; Kendall Tau 0.15 at $\mathrm{p} \leq 0.007167$ ); a weak inverse reliable correlation between the DC concentration in blood serum and liver tissues (Gamma 0.12 at $\mathrm{p} \leq 0.042695$; Kendall Tau -0.11 at $\mathrm{p} \leq 0.042695$ ) was found as well.

Three nonparametric correlation analysis methods revealed at a DC concentration in serum and brain tissues within the norm, the weak reliable correlation between the DC concentrations in blood serum and brain tissues is determined using the Spearman's correlation coefficient $(0.21$ at $\mathrm{p} \leq 0.010654)$. Using the gamma correlation coefficient and Kendell Tau correlations, the weak direct reliable correlation between the DC concentration in blood serum and brain tissues (Gamma 0.16 at $\mathrm{p} \leq 0.007167$; Kendall Tau 0.15 at $p \leq 0.007167$ ), as well as the weak inverse reliable correlation between the DC concentration in serum and liver tissues (Gamma -.12 at $\mathrm{p} \leq 0.042695$; Kendall Tau -0.11 at $\mathrm{p} \leq 0.042695$ ) were identified. A study of free radical processes in rats revealed a nonlinear change in the content of diene conjugates and malondialdehyde in blood plasma, red blood cells, and liver tissue of healthy small experimental animals against a background of changes in the state of the environment; the parameters of free radical oxidation are consistent with the dynamics of the geophysical F-index of phase fluctuations characterizing changes in the external environment. [3].

\section{CONCLUSION}

New results of a nonparametric correlation analysis to assess the relationship between the distribution of concentration of diene conjugates in blood serum and tissues of white outbred rats were presented. 


\section{REFERENCES}

[1] D. Kirmizis, A. Papagianni, F. Dogrammatzi et al., Effects of simvastatin on markers of inflammation, oxidative stress and endothelial cell apoptosis in patients on chronichemodialysis, J. Atheroscler. Thromb. 17(12) (2010) 1256-1265.

[2] N. Traverso, S. Menini, E.P. Maineri, Malondialdehyde, a lipoperoxidation-derived aldehyde, can bring about secondary oxidative damage to proteins, J. Gerontol. A Biol. Sci. Med. Sci. 59(9) (2004) B890-B895.

[3] A.D. Mooradian, D. Reinacher, J.P. Li, J. Pinnas, Malondialdehyde modifi cations of proteins in vitro is enhanced in the presence of acetaldehyde, Nutrition 17(7-8) (2001) 619-622.

[4] D.A. Ksejko, The processes of peroxide oxidation of lipids in norm and pathology, in: The system of lipid peroxidation - antioxidants in health and disease, Vector-P, Ulyanovsk, 2008, pp. 6-48.

[5] I.V. Kudaeva, L.B. Masnavieva, Methods of evaluation of oxidative status in laboratory practice, Med. alphabet 1(2) (2015) 14-18.
[6] R.U. Khabrieva (ed.), Manual on experimental (preclinical) study of new pharmacological substances, Medicine, Moscow, 2005, 832 p.

[7] S.V. Uglanova, M.V. Popov, S.V. Kurova et al., Stabilization of antioxidant enzymes in complexes and conjugates with block copolymers: prospects for the treatment of diseases of the Central nervous system, Bull. of Moscow Univer., Chem. 51(3) (2010) 227-234.

[8] N.I. Tarasov, A.T. Teplyakov, E.V. Malakhovich, The state of lipid peroxidation, antioxidant protection of blood in patients with myocardial infarction, burdened by circulatory insufficiency, Rubbed. Archive 12 (2002) 12-15.

[9] N.P. Chesnokova, Typical pathological processes, Saratov medical Univer., Saratov, 2004, pp. 132-136.

[10] N.P. Chesnokova, E.V. Ponukalina, M.N. Bizenkova, General characteristics of sources of free radical formation and antioxidant systems, Success of modern natural sci. 7 (2006) 37-41. 